\title{
Immunolocalization of the Smooth Muscle-Specific Protein Calponin in Complex and Mixed Tumors of the Mammary Gland of the Dog: Assessment of the Morphogenetic Role of the Myoepithelium
}

\author{
A. Espinosa de los Monteros, M. Y. Millán, J. Ordás, L. Carrasco, C. Reymundo, \\ AND J. Martín DE LAS Mulas \\ Department of Comparative Pathology, Veterinary Faculty, University of Las Palmas de Gran Canaria, \\ Las Palmas de Gran Canaria, Spain (AEM); and \\ Department of Comparative Pathology, Veterinary Faculty (MYM, JO, LC, JMM), and \\ Department of Pathology, Medical School (CR) University of Córdoba, Córdoba, Spain
}

\begin{abstract}
The immunohistochemical expression of the smooth muscle-specific protein calponin was studied to assess the contribution of myoepithelial cells to the histogenesis of spindle cells of complex and mixed tumors of the mammary gland of the dog and the origin of cartilage and bone in mixed tumors. Formalin-fixed tissues from 55 benign and malignant tumors (49 also containing surrounding normal mammary gland) were evaluated. Periacinar and periductal myoepithelial cells of all the 49 normal mammary glands were diffusely stained by the anti-human calponin monoclonal antibody. Calponin was found in $53(98 \%)$ of the tumors studied, reacting with the myoepithelium-like cells of $86 \%$ of benign tumors and their remnants in $85 \%$ of malignant tumors. Five different types of calponin-immunoreactive myoepithelial cells were identified: hypertrophic myoepithelial cells, fusiform cells, stellate myoepithelial cells, rounded (myoepithelial) cells, and chondroblasts. Differences in staining intensity and staining pattern among these five types of cells suggested a transition of myoepithelial cells to chondroblasts. Stromal myofibroblasts also showed calponin immunoreactivity, but they did not react with a cytokeratin 14 monoclonal antibody, which recognizes myoepithelial cells in mammary gland. Calponin appears to be a very sensitive marker of normal and neoplastic myoepithelium in the canine mammary gland, and its identification in different cell types of complex and mixed tumors of the mammary gland of the dog suggests a major histogenetic role for myoepithelial cells.
\end{abstract}

Key words: Calponin; complex tumors; dogs; immunohistochemistry; mammary gland; mixed tumors; myoepithelium.

Canine mammary gland tumors show great histomorphologic heterogeneity, and in addition to epithelial cells, they frequently have spindle cells (complex tumors) and cartilage, bone, or fat (mixed tumors). ${ }^{23}$ Spindle cells of complex and mixed tumors have been traditionally assigned a myoepithelial cell origin, ${ }^{18}$ but results concerning the comparison of their immunophenotype with that of normal myoepithelium are conflicting. ${ }^{9,33,35}$ Three lines of thinking have developed about the origin of cartilage and bone in mixed tumors: metaplasia from epithelial cells, ${ }^{24}$ metaplasia from connective tissue, ${ }^{33}$ and metaplasia from myoepithelial cells. ${ }^{9,27,31,32}$

Canine complex and mixed mammary gland tumors show great similarities to human salivary gland pleomorphic adenoma, a tumor characterized by variable mixtures of epithelial and mesenchymal components. ${ }^{11}$ Pleomorphic adenoma (or benign mixed tumor) of the breast is a rare benign neoplasm similar to the benign mixed tumor of the canine mammary gland. ${ }^{2}$ The recent demonstration of calponin, a marker of a terminal smooth muscle differentiation, ${ }^{14}$ in the majority of well-differentiated myoepithelium-like cells and significant proportions of dedifferentiated modified (myxoid, chondroid, hyaline) and transformed (solid epithelioid, squamous, basalioid-cribriform) myoepithelia in a series of 65 pleomorphic adenomas ${ }^{29}$ supports the hypothesis that myoepithelial cells give rise to the various elements seen in pleomorphic adenoma because of their potential for multidirectional differentation. ${ }^{8,12}$ These findings prompted us to analyze the efficacy (sensitivity and specificity) of an anti-calponin antibody in selectively staining the myoepithelial cell layer of the normal mammary gland of the dog and the myoepithelial cell component of complex and mixed tumors. We also analyzed the value of this myoepithelial cell marker in clarifying the putative role of myoepithelial cells in the genesis of mixed tumors of the dog. 
Table 1. Histologic classification of the 55 canine mammary gland tumors analyzed. ${ }^{23}$

\begin{tabular}{lc}
\hline \multicolumn{1}{c}{ Tumor Type } & Number \\
\hline Benign tumors & \\
Duct papilloma & 5 \\
Complex adenoma & 4 \\
Benign mixed tumor & 4 \\
Fibroadenoma & 1 \\
Total & 14 \\
Malignant tumors & \\
Complex carcinoma & 27 \\
Carcinoma in benign mixed tumor & 13 \\
Carcinosarcoma & 1 \\
Total & 41 \\
Total & 55 \\
\hline
\end{tabular}

\section{Materials and Methods}

\section{Case selection}

Fifty-five mammary gland biopsy or mastectomy specimens that were surgically removed from dogs between 1998 and 2000 were collected from the archives of the Department of Comparative Pathology, University of Córdoba, Spain. The cases reported in this study were all examined histologically (hematoxylin and eosin (HE)-stained sections) before being examined immunohistochemically so they could be reclassified according to the new World Health Organization classification of tumors of the mammary gland of the dog. ${ }^{23}$ The 55 specimens included 14 benign and 41 malignant complex and mixed tumors (Table 1). Unaltered mammary gland tissue was found in the vicinity of 49 tumors (Table 2). All tissues had been fixed in $10 \%$ neutral buffered formalin and embedded in paraffin.

\section{Calponin immunostaining}

The monoclonal antibody used in this study was a mouse monoclonal anti-human calponin (clone CALP, DAKO Corp., Burlingame, CA) diluted 1:400 in phosphate-buffered saline (PBS), $\mathrm{pH} 7.4$, containing $10 \%$ normal goat serum. Sections $4-5 \mu \mathrm{m}$ thick from at least one representative block of each tumor were deparaffined, rehydrated in graded alcohols, and incubated with 3\% hydrogen peroxidase in methanol for 30 minutes to block endogenous peroxidase activity. Heat-induced antigen retrieval (water bath at 95-99 C) with $10 \mathrm{mM}$ citrate buffer ( $\mathrm{pH} 6.0,8$ minutes) was used. After cooling, slides were covered with $10 \%$ normal goat serum in PBS for 30 minutes before incubation with the primary antibody for 18 hours at $4 \mathrm{C}$, and the avidin-biotin peroxidase complex (ABC) method was applied (Vector Laboratories, Burlingame, CA). The chromogen, $0.5 \%$ 3,3'diaminobenzidine tetrahydrochloride (Sigma Chemical Co., St. Louis, MO) diluted 1: 10 in $0.05 \mathrm{M}$ Tris containing $0.3 \%$ hydrogen peroxide, was applied to the slides for 1-2 minutes at 20-22 C. Slides were counterstained with Harris's hematoxylin. Negative controls were obtained by omitting the primary antibody and substituting the primary antibody for mouse ascites fluid diluted $1: 400$. Normal mammary gland tissue served as an internal positive control in every assay.

\section{Evaluation of immunohistochemical data}

Multiple fields on each slide were examined, and positivity was indicated by the presence of distinct brown cytoplasmic staining. The immunostaining was evaluated separately, and results were based upon the consensus of at least two observers. The number of positive cells was determined as a percentage of the total number of cells observed on each slide. Thus, the semiquantitative scoring (SQS) was as follows: $-=$ no stained cells; $+=$ less than $20 \%$ positive cells; $++=20-59 \%$ positive cells; $+++=$ more than $60 \%$ positive cells. The intensity of positivity was evaluated on a 3 -point scale $(1 i, 2 i, 3 i)$. Both the SQS system and the in-

Table 2. Characterization of cell types and expression of calponin* in normal mammary gland and mammary tumors of the dog.

\begin{tabular}{|c|c|c|c|c|c|c|c|c|}
\hline \multirow[b]{2}{*}{ Tumor Types } & \multirow[b]{2}{*}{ No. Tumors } & \multicolumn{7}{|c|}{ Cell Types $\dagger$} \\
\hline & & $\mathrm{EC}$ & MEC & HMEC & FMEC & SMEC & RMEC & $\mathrm{CHB}$ \\
\hline Normal mammary gland & 49 & 0 & 49 & 0 & 0 & 0 & 0 & 0 \\
\hline \multicolumn{9}{|l|}{ Benign tumors } \\
\hline Duct papilloma & 5 & 0 & 5 & 5 & 0 & 0 & 0 & 0 \\
\hline Complex adenoma & 4 & 0 & 3 & 2 & 4 & 1 & 0 & 0 \\
\hline Benign mixed tumor & 4 & 0 & 3 & 4 & 3 & 3 & 4 & 2 \\
\hline Fibroadenoma & 1 & 0 & 1 & 0 & 0 & 0 & 0 & 0 \\
\hline \multicolumn{9}{|l|}{ Malignant tumors } \\
\hline Complex carcinoma & 27 & 0 & 22 & 22 & 20 & 20 & 0 & 0 \\
\hline Carcinoma in benign tumor & 13 & 0 & 13 & 12 & 10 & 7 & 7 & 4 \\
\hline Carcinosarcoma & 1 & 0 & 0 & 0 & 0 & 0 & 0 & 0 \\
\hline
\end{tabular}

* Number of tumors positive for specific cell type.

$\dagger \mathrm{EC}=$ epithelial cells; MEC = myoepithelial cells; HMEC = hypertrophic myoepithelial cells; FMEC = fusiform myoepithelial cells; $\mathrm{SMEC}=$ stellate myoepithelial cells; $\mathrm{RMEC}=$ rounded myoepithelial cells; $\mathrm{CHB}=$ chondroblasts. 
tensity scoring (IS) were analyzed in all types of immunoreactive cells observed.

\section{Cytokeratin immunostaining}

A prediluted monoclonal antibody against cytokeratin 14 (Biogenex Laboratories, San Ramon, CA) was used to elucidate the myoepithelial or myofibroblastic nature of calponin-positive stromal cells in selected tumors. This antibody recognizes keratin protein 14 and reacts with canine epithelial and basal/myoepithelial cells of the normal, dysplastic, and tumorous mammary gland. ${ }^{16}$ The $\mathrm{ABC}$ immunohistochemical technique was applied using the same antigen unmasking method.

\section{Results \\ Normal mammary gland $(n=49)$}

All myoepithelial cells of ducts and acini (MEC) reacted with the anti-calponin monoclonal antibody, but epithelial cells were unreactive (Fig. 1). Immunoreactive products were distributed homogeneously throughout the cell cytoplasm. SQS was +++ , and IS was $3 i$. The smooth muscle walls of blood vessels also reacted strongly to this antibody and provided good internal positive controls. When the skin was included in the tissue section, myoepithelial cells of cutaneous apocrine glands and arrector pili muscles were also homogeneously stained.

\section{Complex tumors $(n=36)$}

Duct papilloma $(\mathrm{n}=5)$. All five of these tumors consisted of multiple papillary growths within preexisting ducts, which had two different types of cells (HE staining): large, polygonal cells with clear cytoplasm (hypertrophic myoepithelial cells [HMEC]) arranged in several layers over the connective-vascular stromal core and a single inner layer of smaller, epitheliumlike cells. Calponin-immunoreactive cells were found in all tumors at two different locations: the continuous layer of periductal, flattened spindle cells not visible in HE-stained sections (myoepithelial cells [MEC]) and the HMEC of the papillomatous growths (Fig. 2, Table 2). Calponin immunoreactivity was homogeneous within the cell cytoplasm in MEC and homogeneous with or without membrane reinforcement in HMEC. The SQS was +++ , and the IS was $3 i$ for MEC cells and variable $(2 i-3 i)$ for HMEC. The inner epithelial cell layer was unreactive.

Complex adenomas $(\mathrm{n}=4)$. HE staining of these tumors revealed the intimate admixture of inner epithelium-type neoplastic cells, usually arranged in tubular fashion, and fusiform or, less frequently, stellate cells lying in abundant, faintly eosinophilic matrix and arranged in solid nests. These stellate cell nests were small and closely apposed to individual neoplastic tubules, sometimes pushing and concealing their lumina, or were bigger and isolated in the interstitium. Occasionally, they were seen emerging from the walls of preexisting ducts. The neoplasms were encapsulated, there was no necrosis or atypia, and the mitotic activity was low. Calponin-immunoreactive cells were found in all tumors (Fig. 3, Table 2). MEC formed a monolayer around luminal epithelium-type structures $(n=$ 3 tumors), and immunoreactive products were homogeneous within the cell cytoplasm (SQS $=+++$; IS $=3 i$ ). HMEC formed a monolayer around luminal epithelium-type structures ( $n=1$ tumor), and immunoreactive products were homogeneous within the cell cytoplasm (SQS $=+++$; IS $=3 i$ ). Fusiform MEC (FMEC) formed nodules either above or below of the layer of MEC ( $n=4$ tumors), and immunoreactive products were homogeneous within the cell cytoplasm $(\mathrm{SQS}=+$ to $++;$ IS $=2 i$ to $3 i)$. Stellate MEC (SMEC) were arranged in solid nests and intermingled with FMEC ( $n=1$ tumor), and immunoreactive products were homogeneous within the cell cytoplasm ( $\mathrm{SQS}=+$; IS $=2 i$ ). The most peripherally located cells of FMEC and SMEC nests showed the strongest reactivity, with a gradual decrease in staining of inner cells (Fig. 3). Among SMEC, the intensity of the staining was fainter as the number of cytoplasmic projections increased.

Complex carcinomas $(\mathrm{n}=27)$. Histologically, complex carcinomas differed from their benign counterparts in at least one of the following features: 1) atypia in the epithelial component of the tumor growth; 2) infiltrative growth; 3) high mitotic activity and cellularity and/or 4) necrosis. Nests of FMEC or SMEC were similar to those observed in complex adenomas, although they were more frequently isolated from the epithelial component (purely interstitial). Immunohistochemically, types of cells reacting with calponin antibody were the same as in complex adenomas, but their number and distribution were different (Table 2). Thus, MEC were found in 22 of 27 tumors, but they appeared as incomplete bands around neoplastic epithelial tubules, as solid nests, or as trapped remnants. Immunostaining was homogeneous within the cell cytoplasm in all cases, and the SQS was variable (from + to ++ ). The IS was variable from $3 i$ to $1 i$ (the lower the amount of remnants, the lower the intensity of staining). In three tumors, this layer was either complete or focally incomplete, indicating the in situ (Fig. 4) or microinvasive (Fig. 5) nature of the poorly differentiated epithelial growth, respectively. In these three tumors, SQS was +++ and IS was $3 i$. HMEC were found in 22 of 27 tumors. In most tumors, they formed a monolayer alternating with $\mathrm{MEC}$ (Fig. 5), whereas in some tumors they formed two or three layers of cells forming the base of predominantly papillary growths (Fig. 6). Calponin immunoreactivity was homogeneous within the cell cytoplasm with or without membrane reinforcement ( $\mathrm{SQS}=++$; IS $=2 i$ ). 


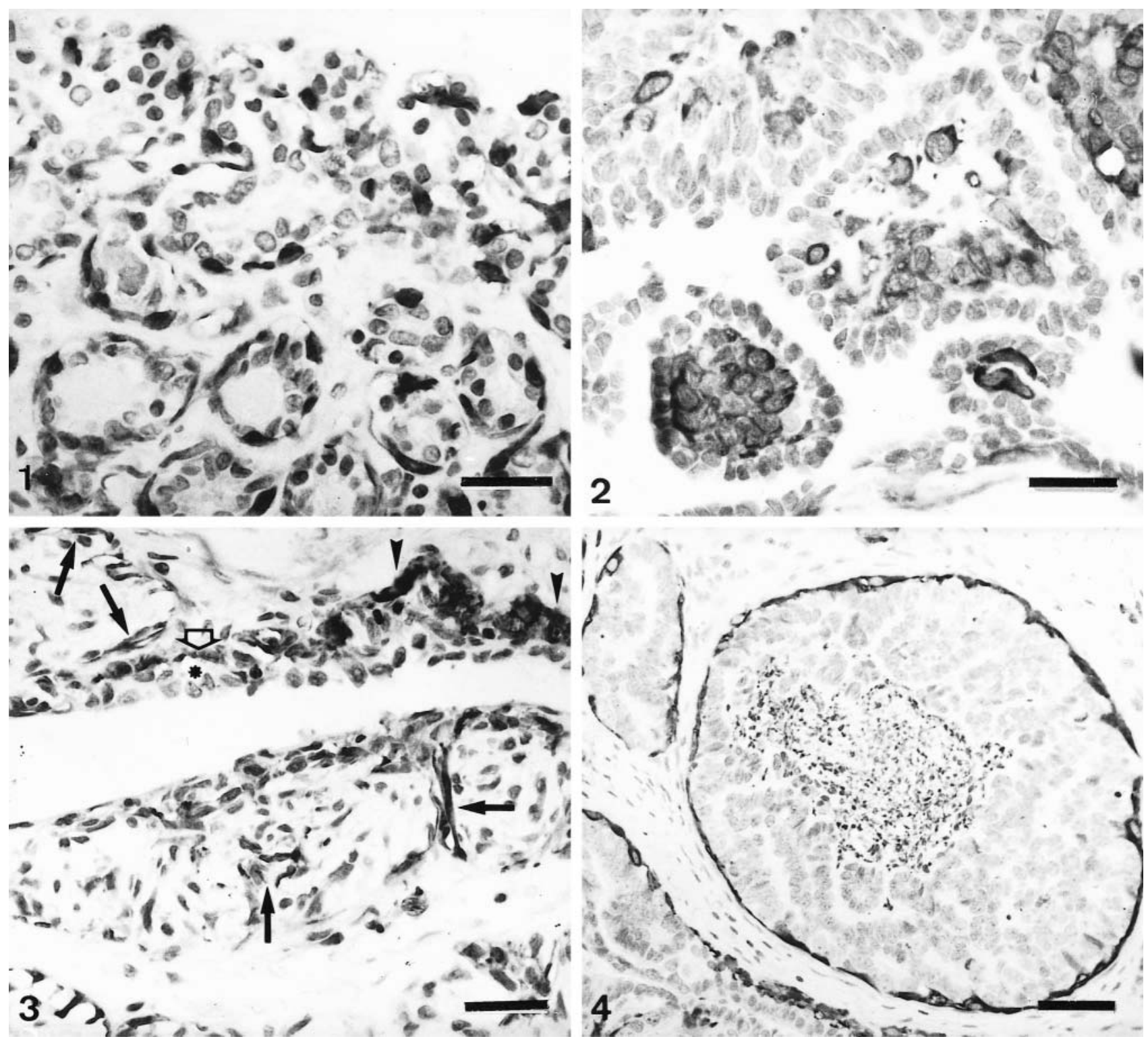

Fig. 1. Normal mammary gland; dog. Several acini with two layers of epithelial cells are shown. The inner layer (epithelial cell layer) is unreactive with the calponin antibody, and the outer layer (myoepithelial cell layer) is positive. Calponin-immunoreactive products are visible in the cell cytoplasm. Semiquantitative scoring is +++ , and intensity scoring is $3 i$. ABC method, Harris's hematoxylin counterstain. Bar $=12 \mu \mathrm{m}$.

Fig. 2. Mammary gland duct papilloma; dog. Papillae are shown on cross section. Calponin-immunoreactive cells are visible at the papillomatous cores as large, polygonal cells (hypertrophic myoepithelial cell [HMEC] type) with a diffuse cytoplasmic staining pattern. Semiquantitative scoring is +++ , and intensity scoring is $3 i$. ABC method, Harris's hematoxylin counterstain. Bar $=12 \mu \mathrm{m}$.

Fig. 3. Mammary gland complex adenoma; dog. Nests of fusiform cells emerge from the wall of a duct. Calponinimmunoreactive cells include myoepithelial cell (MEC) type (open arrow), hypertrophic myoepithelial cells (HMEC; arrowheads), and fusiform myoepithelial cells (FMEC; arrows). The inner epithelial cells of the wall of the duct are unreactive (asterisk). Semiquantitative and intensity score for both MEC and HMEC are +++ and $3 i$; those of FMEC are ++ and $2 i$, respectively. FMEC located at the periphery of the nests are more strongly stained than are FMEC within the nest. ABC method, Harris's hematoxylin counterstain. Bar $=12 \mu \mathrm{m}$.

Fig. 4. Mammary gland complex carcinoma; dog. Atypical neoplastic epithelial cells filling up the lumina of mammary ducts are surrounded by a continuous layer of flattened, calponin-immunoreactive cells, indicating the in situ nature of the epithelial growth. Semiquantitative scoring is +++ , and intesity scoring is $3 i$. ABC method, Harris's hematoxylin counterstain. Bar $=25 \mu \mathrm{m}$. 
Occasionally, HMEC had vacuolated cytoplasm (Fig. 5). FMEC and SMEC were immunoreactive in 20 of 27 tumors, and their immunostaining was homogeneous within the cell cytoplasm. SQS was ++ for FMEC and + for SMEC, and IS was variable from $2 i$ to $1 i$ for both types of cells. In some tumors, FMEC and HMEC were observed next to each other. In these areas, the rupture of the basal lamina was evident. In addition to the four types of immunoreactive cells already described, fusiform cells forming fascicles were observed either surrounding (completely or incompletely) the neoplasm or within it in five tumors. Cytokeratin detection was used to elucidate the nature of these calponin-positive stromal cells. Cytokeratin 14 monoclonal antibody reacted with MEC, HMEC, FMEC, and SMEC but did not react with the fusiform stromal cells that reacted with the calponin antibody (Fig. 7). These cells were not observed in benign tumors, and because of their morphology (fibroblastlike), location (stromal), and immunophenotype (cytokeratin negative), they were identified as myofibroblasts.

\section{Mixed tumors $(n=19)$}

Benign mixed tumors $(\mathrm{n}=4)$. HE staining of these tumors revealed benign cells morphologically resembling epithelial components (inner luminal and/or myoepithelial) and mesenchymal cells that produced cartilage $(n=2)$ or cartilage and bone $(n=2)$. Epithelial components were usually arranged in tubular fashion, and FMEC formed groups lying in abundant, faintly eosinophilic matrix. There were also tumor cell nests composed of FMEC, SMEC, and rounded cells lying in a deeply basophilic matrix. The latter were identified as areas of early chondroid differentiation (Fig. 8) and were frequently observed in the vicinity of mature cartilage.

Immunohistochemically, all four types of calponinpositive cells already described in complex adenomas and carcinomas were seen in those areas of the tumors with a complex pattern of growth. In three tumors, MEC formed a monolayer around luminal epitheliumtype structures. Immunoreactive products were homogeneous within the cell cytoplasm, and SQS was +++ and IS was $3 i$ (Fig. 8). In four tumors where HMEC were observed, immunoreactive products were homogeneous, with or without membrane reinforcement, within the cell cytoplasm, and SQS was ++ and IS was $2 i-3 i$. In three tumors where FMEC were found, the immunostaining was also homogeneous within the cell cytoplasm, with an average SQS of ++ and an IS of $2 i$. In 3 tumors where SMEC were found, immunoreactive products were homogeneous within the cell cytoplasm, and SQS was + and IS was $2 i$ (Fig. 8 , Table 2). In addition to these four types of calponin- positive cells, rounded MEC (RMEC) found in areas of early chondroid differentiation $(n=4)$ and chondroblasts $(n=2)$ were also stained (Fig. 9, Table 2). RMEC were seen either beneath a peripheral band of FMEC or SMEC, which surrounded the focus (Fig. 9), or intermingled with FMEC and SMEC within the focus. Immunostaining was homogeneous within the cell cytoplasm, and SQS was + and IS was from $3 i$ to $2 i$. Immunoreactive chondroblasts were usually located at the periphery of the cartilage focus, although sometimes they were found within it (Fig. 10). The number of calponin-positive chondroblasts and the IS were low in both cases ( $\mathrm{SQS}=+$; IS $=1 i$; respectively) and their pattern of staining varied from homogeneous to dotty within the cytoplasm, giving the impression of a progressive disappearance from homogeneous to dotty. Two benign mixed tumors contained areas of bone, which were always unreactive with the calponin antibody. In one of the benign mixed tumors, the MEC layer was disrupted at the level of atypical intraductal proliferations. The focal absence of MEC had been overlooked in HE staining, and the tumor was reclassified as in situ microinvasive carcinoma in benign tumor.

Carcinoma in benign tumor ( $\mathrm{n}=13)$. Histologically, these tumors were similar to their benign counterparts except that the epithelial luminal component of the tumor had the features of a carcinoma either focally or diffusely. Immunohistochemically, the pattern of staining was also similar, although differences were observed mostly with respect to the MEC layer, which was always disrupted at some point $(n=13)$. Immunostaining was homogeneous within the cell cytoplasm in all tumors, and the SQS was variable (from + to ++$)$. The IS was variable from $3 i$ to $1 i$; the fewer MEC remnants present, the lower the IS (Fig. 11). HMEC $(n=3)$ (Fig. 11), RMEC $(n=7)$, and chondroblasts $(n=4)$ were also stained, and their pattern of staining was similar to that described for benign mixed tumors. Osteoblasts were unreactive in the five tumors that contained areas of bone, but positive FMEC were observed in the interosseus space in two tumors. In addition to the five types of immunoreactive cells already described, fusiform cells forming fascicles were observed either surrounding completely or incompletely the neoplasm or within it in five tumors. These cells did not react with cytokeratin 14 monoclonal antibody, but all types of myoepithelial cells (MEC, HMEC, FMEC, SMEC, and RMEC) did. Isolated chondroblasts reacted with cytokeratin 14 antibody in three tumors, and the staining pattern was similar to that of calponin antibody. Epithelial cells were negative to anti-calponin antibody.

Low-cellularity fibroadenoma $(\mathrm{n}=1)$ : The epithelial component of the tumor was surrounded by a con- 


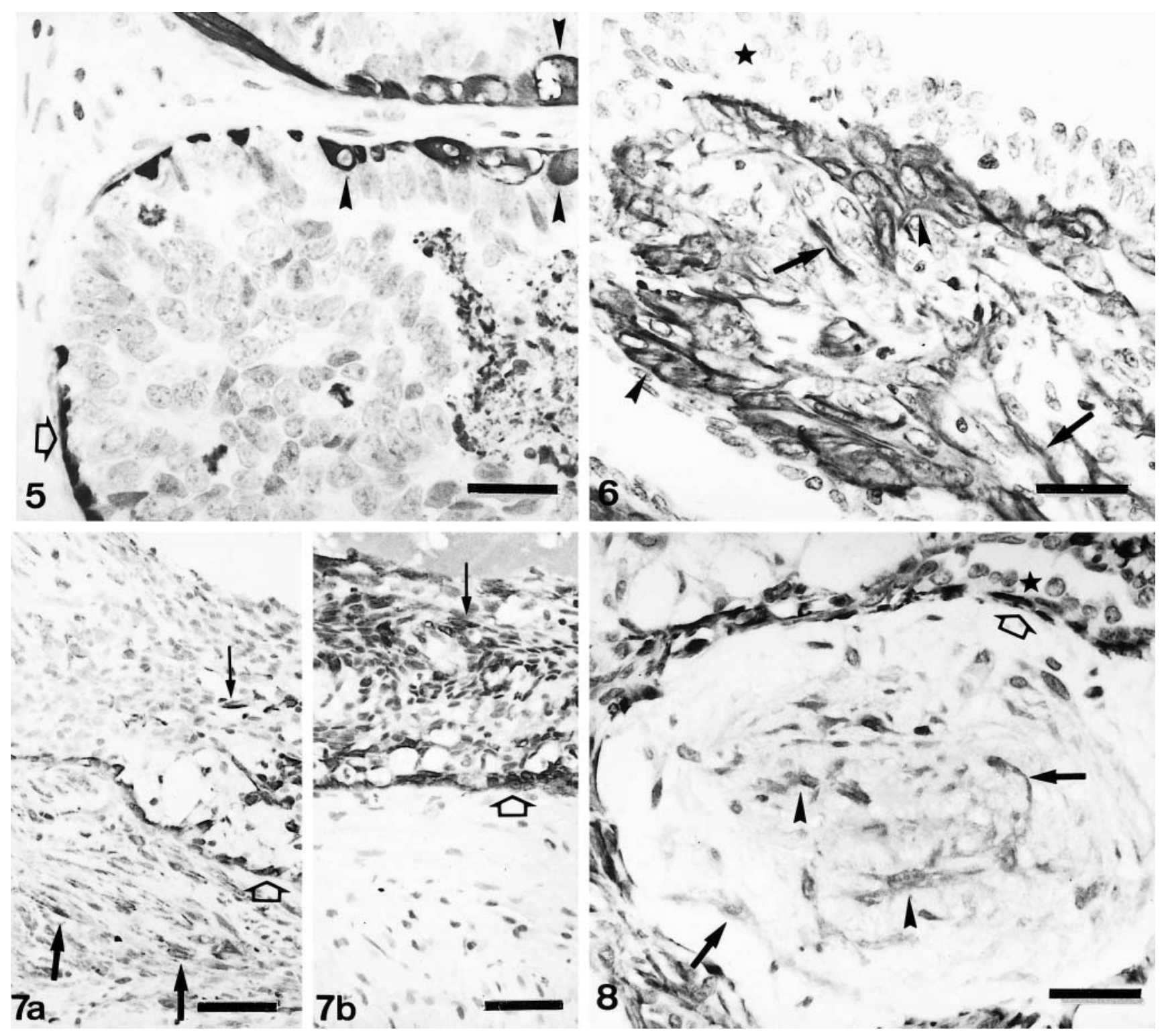

Fig. 5. Mammary gland complex carcinoma; dog. Atypical neoplastic epithelial cells fill up the lumen of a mammary duct and the edge of another duct. Central necrosis and mitoses are present. There are two types of calponin-immureactive cells: myoepithelial cell (MEC) type (open arrow) and hypertrophic myoepithelial cells (HMEC; arrowheads). Patterns of immunostaining are homogeneous within the cytoplasm (MEC and HMEC). Some HMEC have vacuolated cytoplasm. Semiquantitative and intensity scoring for both types of cell are +++ and $3 i$, respectively. Calponin-positive cells incompletely surround the atypical epithelial intraductal growth (highlighting its microinvasive nature). ABC method, Harris's hematoxylin counterstain. Bar $=12 \mu \mathrm{m}$.

Fig. 6. Mammary gland complex carcinoma; dog. Neoplastic papilla. Calponin-immunoreactive cells include a single or double layer of hypertrophic myoepithelial cells (HMEC; semiquantitative scoring +++ , intensity scoring $2 i$; arrowheads) and fusiform myoepithelial cells (FMEC; semiquantitative scoring + , intensity scoring $3 i$; arrows). The pattern of staining of HMEC is homogeneous within the cell cytoplasm with membrane reinforcement. Epithelial cells are unreactive (star). ABC method, Harris's hematoxylin counterstain. Bar $=12 \mu \mathrm{m}$.

Fig. 7. Mammary gland complex carcinoma; dog. Neoplastic duct with central necrosis. Fig. 7A. Calponin-immunoreactive cells include a basal layer of flattened myoepithelial cells (MEC; open arrow), fusiform cells (FMEC) above (thin arrow) and FMEC below (thick arrows) the MEC. Fig. 7B. Cytokeratin 14-immunoreactive cells include a basal layer of flattened MEC (open arrow) and FMEC above (thin arrow), but the FMEC below the MEC layer are unreactive. ABC method, Harris's hematoxylin counterstain. Bar $=25 \mu \mathrm{m}$.

Fig. 8. Mammary gland benign mixed tumor; dog. A nest of fusiform and stellate cells in abundant matrix (early 
tinuous band of spindle-shaped calponin-positive cells (MEC).

Carcinosarcoma $(\mathrm{n}=1)$. No immunoreactive cells were found.

\section{Discussion}

Periacinar and periductal MEC of all the 49 normal mammary glands were diffusely stained by the antihuman calponin monoclonal antibody employed in this study. In addition, calponin was found in 53 (98\%) of the tumors studied, reacting to the myoepithelium-like cells of $86 \%$ of benign tumors and $85 \%$ of malignant tumors. The immunoreactivity was observed in the hypertrophic MEC of $78 \%$ of benign tumors and $83 \%$ of malignant tumors; the FMEC of all complex adenomas, $75 \%$ of benign mixed tumors, $74 \%$ of complex carcinomas, and $77 \%$ of carcinomas in benign tumors; the SMEC of $25 \%$ of complex adenomas, $75 \%$ of benign mixed tumors, $74 \%$ of complex carcinomas, and $54 \%$ of carcinomas in benign tumors; the RMEC of all benign mixed tumors and $54 \%$ of carcinomas in benign tumors; and the chondroblasts of $50 \%$ of benign mixed tumors and $31 \%$ of carcinomas in benign tumors.

Normal and neoplastic myoepithelium have a complex cytoskeletal immunophenotype. Because of its dual epithelial and smooth muscle characteristics, high-molecular-weight cytokeratins and smooth muscle actins and muscle actin (clone HFF35) have been used as markers of myoepithelium. ${ }^{9}, 13,16,22,33,35,37$ In addition, unexpected proteins such as glial fibrillary acidic protein and S100 protein have also been demonstrated by immunohistochemical methods. ${ }^{9}, 13,22,37$ However, expression of high-molecular-weight cytokeratins has been found not only in MEC but also in luminal cells and so-called intermediate cells. ${ }^{17,34}$ In addition, several investigators have demonstrated the low sensitivity of these cytokeratins as markers of MEC..$^{37}$ Currently, the myofilament component of myoepithelium is considered a more sensitive and specific target for the identification of MEC in proliferative and neoplastic lesions of the breast. ${ }^{37}$

Calponin is a 34-k smooth muscle-specific protein implicated in the regulation of smooth muscle contraction as a result of its ability to inhibit actin-activated MgATPase of smooth muscle myosin. ${ }^{5}$ As yet, no analogues of calponin have been found in nonmuscle cells. Calponin is a highly sensitive marker of myo- epithelial cells in human breast tissue, including breast carcinomas, ${ }^{6,7}$ and appears to be a more specific marker of MEC than muscle actin. ${ }^{36}$ It is considered a very useful marker in differentiating benign and in situ lesions from invasive carcinoma of the breast. ${ }^{7,36}$ In canine tumors, the integrity of the MEC layer is highlighted by calponin immunostaining and allows differentiation of in situ from microinvasive lesions.

The myoepithelial nature of the spindle-cell component of complex and mixed tumors of the dog and of the mesenchymal components of mixed tumors has been analyzed by comparing the immunophenotype of those tumor components with that of normal myoepithelium, but results have been conflicting. Destexhe et al. ${ }^{9}$ confirmed the MEC origin of interstitial spindle and stellate cells by using antibodies to keratin 19, vimentin, alpha-actin, and $\mathrm{S} 100$ protein as markers and suggested a progressive transformation from resting MEC to cartilage. Griffey et al. ${ }^{16}$ suggested that the stromal proliferation and metaplasia that occur within mixed mammary tumors could be derived from myoepithelium. This hypothesis was supported by their observation of the myoepithelium-specific 312C8-1 antibody reactivity of some spindle cells within the proliferative stroma in 10 of 12 mixed mammary tumors studied. ${ }^{16}$ Other immunohistochemical results support this hypothesis and provide evidence of a stem cell origin with divergent differentiation based on the coexpression of different antigens by myoepitheliumlike and connective tissue cells in canine mixed tumors $^{13,19}$ and human pleomorphic adenoma of the breast. ${ }^{10}$ These antigens included cytokeratins, vimentin, desmin, neurofilament, and alpha-actin. Earlier electron microscopic and histochemical studies documented a transition of MEC to cartilage in canine benign mixed mammary tumors. ${ }^{4,21,31,32}$ However, evaluation with antibodies to keratins 14 and 17 and alpha smooth actin revealed that tumors histomorphologically assumed to be of a myoepithelial origin did not show the immunohistochemical features of MEC, ${ }^{33-35}$ suggesting that cartilage and/or bone formation in canine mammary tumors results from stromal metaplasia, as previously suggested. ${ }^{3,26}$

Our findings are in agreement with those of other researchers 9,16 and support the hypothesis of a progressive transformation from MEC to FMEC and SMEC in canine complex mammary tumors and from FMEC and SMEC to RMEC of early chondroid dif-

$\leftarrow$

chondroid differentiation area). Calponin-immunoreactive cells include fusiform myoepithelial cells (FMEC; arrows) and stellate myoepithelial cells (SMEC; arrowheads). In addition, a monolayer of spindle, flattened cells (open arrow) that surrounds both the unreactive epithelial cells (star) and the early chondroid differentiation focus is also positive (myoepithelial cell $[\mathrm{MEC}]$ type). ABC method, Harris's hematoxylin counterstain. Bar $=12 \mu \mathrm{m}$. 

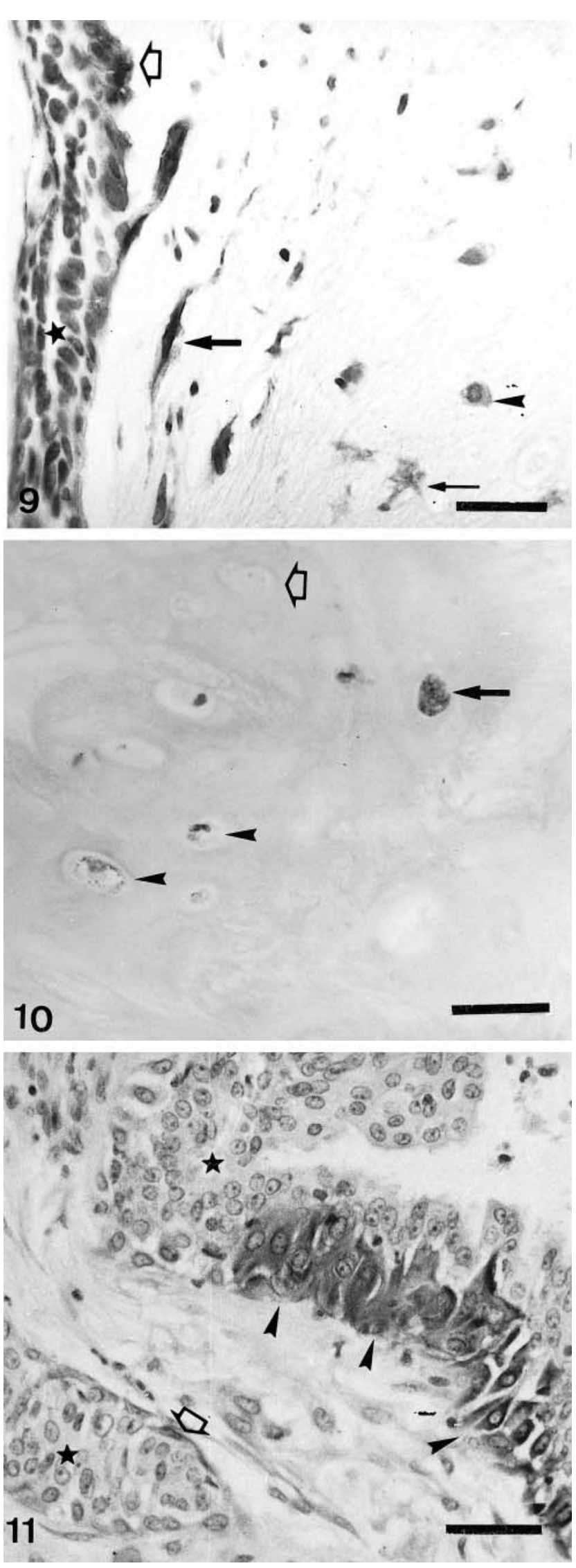

ferentiation areas in canine mixed mammary tumors. They also suggest a possible transformation from any of these cell types to chondroblasts. Changes in the composition of the extracellular matrix would accompany this transformation. A diffuse accumulation of chondroitin sulfate has been reported to be present almost exclusively in complex and mixed tumors of the mammary gland of the dog. ${ }^{20}$ Because of the expression of the 3B3 epitope for chondroitin sulfate in immature cartilage, the spindle cells of complex tumors are thought to be precursors of the cartilage in mixed tumors. ${ }^{20}$ The histogenetic role of MEC in pleomorphic adenoma of the human salivary glands has been recently assessed by the demonstration of calponin in the majority of more highly differentiated myoepithelium-like cells and significant proportions of dedifferentiated modified (myxoid, chondroid, hyaline) and transformed (solid epithelioid, squamous, basalioidcribiform) myoepithelia in a series of 65 pleomorphic adenomas. ${ }^{29}$ Salivary and mammary glands share a common embryologic origin, and similarities exist between canine complex and mixed tumors of the mammary gland and the human pleomorphic adenoma of the salivary glands. In the complex and mixed tumors included in this study, we identified some of the cell types described in the human tumor, including the more highly differentiated myoepithelium-like cells

$\leftarrow$

Fig. 9. Mammary gland benign mixed tumor; dog. A neoplastic duct (left) and a cartilaginous focus (right). Calponin-immunoreactive cells include a monolayer of myoepithelial cells (MEC; open arrow) around the unreactive epithelial cells (star), fusiform MEC (FMEC; thick arrow), and stellate MEC (SMEC; thin arrow) at the periphery of the cartilaginous focus and rounded MEC (RMEC; arrowhead) located at the most inner part of this focus. One unreactive chondroblast is seen at the low right corner. $\mathrm{ABC}$ method, Harris's hematoxylin counterstain. Bar $=12 \mu \mathrm{m}$.

Fig. 10. Mammary gland benign mixed tumor; dog. Well-differentiated cartilage. Calponin-immunoreactive products are observed within the cytoplasm of chondroblasts either homogeneously (arrow) or as scarce dark dots (arrowheads) Unreactive chondroblasts are also present (open arrow). ABC method, Harris's hematoxylin counterstain. Bar $=12 \mu \mathrm{m}$.

Fig. 11. Mammary gland carcinoma in benign tumor; dog. Two neoplastic ducts and intervening stroma are shown. Calponin-immunoreactive cells include an isolated myoepithelial cell (MEC) around one of the ducts (open arrow) and an incomplete layer of hypertrophic MEC (HMEC) surrounding the other duct (arrowheads). Neoplastic epithelial cells (stars) are unreactive. ABC method, Harris's hematoxylin counterstain. Bar $=12 \mu \mathrm{m}$. 
and the myxoid and chondroid types of dedifferentiated modified myoepithelium.

One disadvantage of calponin as a marker of MEC is the fact that it also stains myofibroblasts. Myofibroblasts are cells with a partial smooth muscle phenotype, ${ }^{28}$ and they share with true smooth muscle cells a contractile system composed of 50-70 A actin-containing microfilament bundles. ${ }^{25,28}$ Therefore, antibodies to smooth muscle-restricted proteins used as MEC markers, such as antibodies to smooth muscle actins, muscle actins, and to a lesser extent calponin and smooth muscle myosin-heavy chain, also identify myofibroblasts in the desmoplastic stroma of human, ${ }^{36,37}$ feline, ${ }^{30}$ and canine ${ }^{16,35}$ invasive carcinomas of the mammary gland. In the present study, $25 \%$ of malignant tumors analyzed contained calponin-immunoreactive spindle cells located in the connective tissue surrounding the tumoral growth or within it. Both location and morphology of these cells clearly indicated their myofibroblastic nature in the majority of these tumors. In some other tumors, the staining of these cells with calponin was problematic because some cells were located close to the malignant tubules, creating a false impression of a MEC layer, as previously observed by others. . $^{15,30}$ The absence of reactivity of the calponin-positive stromal cells with the cytokeratin 14 monoclonal antibody, which recognizes basal/myoepithelial cells in normal, dysplastic, and tumorous (benign and malignant) mammary gland tissues of the dog, ${ }^{16}$ allowed their differentiation from MEC.

Calponin is a sensitive and specific marker of the MEC layer of the normal mammary gland of the dog and a sensitive marker of neoplastic myoepithelium. Its identification in significant proportions of the spindle-cell component of complex and mixed tumors and variable proportions of RMEC and chondroblasts in mixed tumors suggests a major histogenetic role of MEC in both types of tumors. The only disadvantage to calponin as a marker is the staining of myofibroblasts, as has been described previously in cats. ${ }^{30} \mathrm{In}$ the dog, myofibroblasts are uniformly stained by muscle actin antibodies in malignant mammary tumors. ${ }^{9,33}$

\section{Acknowledgements}

This work was supported by grants PM98-0164 (Dirección General de Enseñanza Superior e Investigación Científica, Ministerio de Educación, Cultura y Deportes) and PI1999/155 (Consejería de Educación, Cultura y Deportes, Gobierno de Canarias).

\section{References}

1 Ahmed A: The myofibroblast in breast disease. Pathol Annu 25:237-286, 1990

2 Ballance WA, Ro JY, El-Naggar AK, Grignon DJ, Ayala AG, Romsdahl MG: Pleomorphic adenoma (benign mixed tumor) of the breast. An immunohistochemical, flow cytometric, and ultrastuctural study and review of the literature. Am J Clin Pathol 93:795-801, 1990

3 Bloom F: Mammary tumors of the dog. In: Pathology of the Dog and Cat. The Genitourinary System, with Clinical Considerations, pp. 418-424. American Veterinary Publications, Evanston, IL, 1954

4 Bombard D, Sandersleben J: Über die feinstruktur von mammamischtumoren der hündin. II. Das vorkommen von myoepithelzellen in chondroiden arealen. Virchows Arch A Pathol Anat 362:157-167, 1974

5 Carmichael JD, Winder SJ, Walsh MP, Kargacin GJ: Calponin and smooth muscle regulation. J Physiol Pharmacol 72:1415-1419, 1994

6 Dabbs DJ, Gown AM: Distribution of calponin and smooth muscle myosin heavy chain in fine-needle aspiration biopsies of the breast. Diagn Cytopathol 20:203207, 1999

7 Damiani S, Ludvikova M, Tomasic G, Bianchi S, Gown AM, Eusebi V: Myoepithelial cells and basal lamina in poorly differentiated in situ duct carcinoma of the breast. An immunohistochemical study. Virchows Arch A Pathol Anat 434:227-234, 1999

8 Dardick I, van Nostrand AWP, Jeans D, Rippstein P, Edwards V: Pleomorphic adenoma. I. Ultrastuctural organization of "epithelial" regions. Hum Pathol 14:780 797, 1983

9 Destexhe E, Lespagnard L, Degeyter M, Heymann R, Coignoul F: Immunohistochemical identification of myoepithelial, epithelial and connective tissue cells in canine mammary tumors. Vet Pathol 30:146-154, 1993

10 Díaz NM, McDivitt RW, Wick MR: Pleomorphic adenoma of the breast: a clinicopathologic and immunohistochemical study of 10 cases. Hum Pathol 22:12061214, 1991

11 Ellis GL, Auclair PL: Tumors of the salivary glands. In: Atlas of Tumor Pathology, 3rd series, fascicle 17, p. 39. Armed Forces Institute of Pathology, Washington, DC, 1996

12 Erlandson RA, Cardon-Cardo C, Higgins PJ: Histogenesis of benign pleomorphic adenoma (mixed tumor) of the major salivary glands: an ultrastructural and immunohistochemical study. Am J Surg Pathol 8:803-820, 1984

13 Gärtner F, Geraldes M, Cassali G, Rema A, Schmitt F: DNA measurement and immunohistochemical characterization of epithelial and mesenchymal cells in canine mixed mammary tumors: putative evidence for a common histogenesis. Vet J 158:39-47, 1999

14 Gimona M, Herzog M, Vancekerckhove J, Small JV: Smooth muscle specific expression of calponin. Fed Eur Biochem Soc Lett 274:159-162, 1990

15 Gottlied C, Raju U, Greenawald KA: Myoepithelial cells in the differential diagnosis of complex benign and malignant breast lesions: an immunohistochemical study. Mod Pathol 3:135-140, 1990

16 Griffey SM, Madewell BR, Dairkee SH, Hunt JE, Naydan DK, Higgins RJ: Immunohistochemical reactivity of basal and luminal epithelium-specific cytokeratin antibodies within normal and neoplastic canine mammary glands. Vet Pathol 30:155-161, 1993 
17 Guelstein VI, Tchypysgeva TA, Ermilova VD, Ljubimov AV: Myoepithelial and basement membrane antigens in benign and malignant human breast tumors. Int $\mathrm{J}$ Cancer 53:269-277, 1993

18 Hampe JF, Misdorp W: Tumours and dysplasias of the mammary gland. Bull World Health Org 50:111-133, 1974

19 Hellmén E, Lindgren A: The expression of intermediate filaments in canine mammary glands and their tumors. Vet Pathol 26:420-428, 1989

20 Hinrichs U, Rutteman GR, Nederbragt H: Stroma accumulation of chondroitin sulphate in mammary tumours of dogs. Br J Cancer 80:1359-1365, 1999

21 Kaldrymidou E, Kanakoudis G, Tsangaris T, Karagiannopoulou M: Metaplastic stages of myoepithelial cells in canine mammary mixed tumor. Bull Hell Vet Med Soc 37:156-169, 1986

22 Martín de las Mulas J, Espinosa de los Monteros A, Bautista MJ, Gómez-Villamandos JC, Morales C: Immunohistochemical distribution pattern of intermediate filament proteins and muscle actin in feline and human mammary carcinomas. J Comp Pathol 111:365-381, 1994

23 Misdorp W, Else RW, Hellmén E, Lipscomb TP: Histological Classification of Mammary Tumors of the Dog and the Cat, 2nd series, vol. VII. WHO International Histological Classification of Tumors of Domestic Animals. Armed Forces Washington, DC, Institute of Pathology, 1999

24 Monlux AW, Roszel JF, MacVean DW, Palmer TW: Classification of epithelial canine mammary tumors in a defined population. Vet Pathol 14:194-217, 1977

25 Ohtani H, Sasano N: Myofibroblasts and myoepithelial cells in human breast carcinoma. An ultrastructural study. Virchow Arch A Pathol Anat 385:247-261, 1980

26 Palmer TE, Monlux AW: Acid mucopolysaccharides in mammary tumors of dog. Vet Pathol 16:493-509, 1979

27 Pulley LT: Ultrastuctural and histochemical demonstration of myoepithelium in mixed tumors of the canine mammary gland. Am J Vet Res 34:1513-1522, 1973

28 Ryan GB, Cliff WJ, Gabbiani G, Irle C, Montandon D, Statkov PR, Majno G: Myofibroblasts in human granulation tissue. Hum Pathol 5:55-67, 1974
29 Savera AT, Gown AM, Zarbo RJ: Immunolocalization of three novel smooth muscle-specific proteins in salivary gland pleomorphic adenoma: assessment of the morphogenetic role of myoepithelium. Mod Pathol 10:10931100, 1997

30 Sironi G, Faustino AMR, Montemezzo N: Immunodetection of myoepithelial cells in feline mammary tissues by markers of smooth muscle differentiation. Proc Annu Meet Eur Soc Vet Pathol 17:105, 1999

31 Tateyama S, Cotchin E: Alkaline phosphatase reaction of canine mammary mixed tumours: a light and electron microscopic study. Res Vet Sci 23:356-364, 1977

32 Tateyama S, Cotchin E: Electron microscopic observation on canine mixed tumours with special reference to cytoplasmic filamentous components. Am J Vet Res 39: 1479-1501, 1978

33 Vos JH, van den Ingh TSGAM, Misdorp W, Molenbeek FR, van Mil FN, Rutteman GR, Ivanyi D, Ramaekers FCS: Immunohistochemistry with keratin, vimentin, desmin and smooth muscle actin monoclonal antibodies in canine mammary glands: benign tumours and duct ectasias. Vet Q 15:89-96, 1993

34 Vos JH, van den Ingh TSGAM, Misdorp W, Molenbeek FR, van Mil FN, Rutteman GR, Ivanyi D, Ramaekers FCS: Immunohistochemistry with keratin, vimentin, desmin and smooth muscle actin monoclonal antibodies in canine mammary gland: malignant mammary tumours. Vet Q 15:96-102, 1993

35 Vos JH, van den Ingh TSGAM, Misdorp W, Molenbeek FR, van Mil FN, Rutteman GR, Ivanyi D, Ramaekers FCS: Immunohistochemistry with keratin, vimentin, desmin and smooth muscle actin monoclonal antibodies in canine mammary gland: normal mammary tissue. Vet Q 15:102-107, 1993

36 Wang NP, Man BC, Skelly M, Frid MG, Glukhova MA, Koteliansky VE, Gown AM: Antibodies to novel myoepithelium-associated proteins distinguish benign lesions and carcinoma in situ from invasive carcinoma of the breast. Appl Immunohistochem 5:141-151, 1997

37 Yaziji H, Gown AM, Sneige N: Detection of stromal invasion in breast cancer: the myoepithelial markers. Adv Anat Pathol 7:100-109, 2000

Request reprints from Dr. J. Martín de las Mulas, Departamento de Anatomia y Anatomía Patológica Comparadas, University of Córdoba, Edificio de Sanidad Animal, Campus de Rabanales, Carretera Madrid-Cádiz, Km. 396, 14014 Córdoba (Spain). 